\title{
Kinetic Analysis of the Chemical Processes in the Decomposition of Gaseous Dielectrics by a Non-Equilibrium Plasma - Part 2: $\mathrm{SF}_{6}$ and $\mathrm{SF}_{6} / \mathrm{O}_{2}$.
}

\author{
Glauco F. Bauerfeldt and Graciela Arbilla*
}

\author{
Departamento de Físico-Química, Instituto de Química, Universidade Federal do Rio de Janeiro, \\ Sala 408, CT Bloco A, Cidade Universitária, 21949-900, Rio de Janeiro - RJ, Brazil
}

\begin{abstract}
Neste trabalho é realizada a simulação numérica da decomposição em fase gasosa de $\mathrm{SF}_{6} \mathrm{e}$ misturas de $\mathrm{SF}_{6} / \mathrm{O}_{2}$, na presença de silício. São determinadas as velocidades relativas dos processos individuais, o efeito da incerteza dos parâmetros e os coeficientes de sensibilidade. Os resultados são comparados com dados experimentais encontrados na literatura e resultados calculados previamente para a corrosão do silício, a fim de ajustar os parâmetros do modelo. À semelhança do que acontece com o $\mathrm{CF}_{4}$, o principal agente de corrosão é o flúor atômico e a concentração das principais espécies envolvidas depende da composição da mistura. A forma das curvas de sensibilidade segue o formato geral das curvas que representam a velocidade dos processos individuais e a relação entre os coeficientes de sensibilidade calculados para as diferentes etapas de reação é uma medida da contribuição de cada uma ao processo total.
\end{abstract}

In this work, a numerical modelling analysis of the gas-phase decomposition of pure $\mathrm{SF}_{6}$ and $\mathrm{SF}_{6} / \mathrm{O}_{2}$ mixtures, in the presence of silicon was performed. The relative rate of individual processes, the effect of the parameters uncertainties and the sensitivity coefficients were determined. The results were compared with literature experimental data for the plasma etching of silicon and with previous simulated results to adjust the model parameters. As in the $\mathrm{CF}_{4}$ system, the main etching agent is atomic fluorine and the concentration of the major species depends on the composition of the mixture. The shape of the sensitivity curves follows the general shape of the individual rate curves and the ratio between the calculated sensitivity coefficients is closely related to the contribution of each reaction.

Keywords: sensitivity analysis, rate of production analysis, $\mathrm{SF}_{6}$ decomposition

\section{Introduction}

In a previous paper, the plasma chemistry of pure $\mathrm{CF}_{4}$ and $\mathrm{CF}_{4} / \mathrm{O}_{2}$ mixtures has been studied ${ }^{1}$. As discussed in that work, models for the plasma chemistry of $\mathrm{SF}_{6} / \mathrm{O}_{2}$ and $\mathrm{CF}_{4} / \mathrm{O}_{2}$ mixtures have been extensively investigated by different research groups $2-19$. These processes are extremely complex to be modelled and solved, considering all the homogeneous processes in the gas phase and the heterogeneous processes occurring at the gas-solid interface 20 .

In this work, as explained in more detail in Reference 1, the numerical integration is used to obtain a good understanding of the main chemical processes in the gaseous phase and to estimate the relative importance of individual reactions and the sensitivity coefficients $S_{i j}$ for the species (i) towards the model parameters $\left(\lambda_{\mathrm{j}}\right)$. In solving the chemical sub-model,

*e-mail: graciela@iq.ufrj.br the other processes are considered in a parameterised, simplified way. Although limited, this approach enables the analysis of the chemical system without the need of invoking the steady-state approximation and provides information about the key processes.

\section{Formulation of the Models}

The model of Ryan and Plumb14, as well as kinetic data of Ryan ${ }^{11}$, Kopalidis and Jorné17 and Khairallah et al.18, were used as a basis for the present kinetic scheme. Since the main goal of this study was the sensitivity and rate of production analysis ${ }^{21}$, only slight modifications were made in the previous proposed models. The model was discussed by Bauerfeldt and Arbilla 19 .

Experimental data from Smolinsky and Flamm 22, for $\mathrm{CF}_{4} / \mathrm{O}_{2}$ mixtures, were used to choose the boundary conditions. In that work, the total gas number density was $1.6 \times 10^{16}$ $\mathrm{cm}^{-3}(0.5$ Torr) and the gas mixture was excited by a $49 \mathrm{~W}$, 
13.56 MHz discharge. These conditions are not exactly the same as those of the experiments of d'Agostino and Flamm ${ }^{23}$. In their work, the $\mathrm{SF}_{6} / \mathrm{O}_{2}$ mixtures at a total gas number density of $3.0 \times 10^{16} \mathrm{~cm}^{-3}$ (1.0 Torr) in a $5 \mathrm{~cm}$ length aluminium tube with $27 \mathrm{ccSTP} / \mathrm{min}$ flow rate, were excited by a $45 \mathrm{~W}, 27 \mathrm{MHz}$ discharge. The analysis of the stable products was performed by infrared spectroscopy/ gas chromatography and gas chromatography/mass spectrometry. Oxygen and fluorine atoms were observed by emission spectroscopy. Nevertheless, the conditions of the work of Smolinsky and Flamm ${ }^{22}$, for $\mathrm{CF}_{4} / \mathrm{O}_{2}$, were preferred in order to compare the present simulation with the results of Part 11.

Further details on the formulation of this sub-model can be found in our previous papers 1,19 .

\section{The Numerical Method}

The differential equations were solved using the RungeKutta-4-Semi-Implicit Method 24 as implemented in the kinetic program KINAL 25 . The kinetic results were analysed by comparing the relative importance of each reaction, in other words, by calculating the contribution of each step to the total rate of concentration change for each specie. The sensitivity coefficients 26 were calculated by the Direct Decomposed Method 27 in order to estimate the effect of parameters' uncertainties on the predicted concentrations. Since some of the parameters and coefficients, such as electron number density, branching ratios and heterogeneous reaction rate constants, are very difficult to evaluate, an additional test was done by changing some of the parameters within their range of uncertainty.

\section{Results and Discussion}

\section{Pure $\mathrm{SF}_{6}$}

The chemical model for the $\mathrm{SF}_{6}$ and $\mathrm{SF}_{6} / \mathrm{O}_{2}$ plasmas used in the etching of silicon was studied previously in our laboratory 19 . This model consists of a set of dissociation, gas phase recombination, and solid phase association (surface adsorption, reaction and further desorption) reactions. The complete reaction set and boundary conditions may be found in our earlier paper ${ }^{19}$, as well as the results for the kinetic simulation. An initial relevance analysis was also performed in that work. Initial conditions for the simulation are listed in Table 1 and are the same as used in reference 19.

As in our previous work on $\mathrm{CF}_{4}$ and $\mathrm{CF}_{4} / \mathrm{O}_{2}$ systems ${ }^{1}$ and, also, as considered by other authors ${ }^{14}$, we assumed that a negligible loss of free radicals occurs at the walls. The reaction set model and the general approach were very similar to that of pure $\mathrm{CF}_{4}$ system ${ }^{1}$.
Table 1. Numerical simulations initial conditions

\begin{tabular}{ll} 
Temperature & $313 \mathrm{~K}$ \\
Total pressure & $0.5 \mathrm{Torr}$ \\
Flow & $24.37 \mathrm{~cm}^{3} \mathrm{STP} / \mathrm{min}$ \\
Plasma length & $5.0 \mathrm{~cm}$ \\
Initial Concentrations (molecules $\left.\mathbf{c m}^{-3}\right)$ & \\
Total $[\mathrm{M}]$ & $1.54 \times 10^{16}$ \\
{$[\mathrm{~F}]$} & $1.00 \times 10^{10}$ \\
{$[\mathrm{Si}]$} & $1.00 \times 10^{14}$ \\
\hline
\end{tabular}

The experimental results of d'Agostino and Flamm 23 were used for comparison. Evidences from other experimental works 7,11,17,18 were taken into account.

The $\mathrm{SF}_{6}$ dissociation may be assumed to occur by the following set of reactions:

$$
\begin{aligned}
& \mathrm{e}^{-}+\mathrm{SF}_{6} \rightarrow \mathrm{e}^{-}+\mathrm{SF}_{5}+\mathrm{F} \\
& \mathrm{e}^{-}+\mathrm{SF}_{5} \rightarrow \mathrm{e}^{-}+\mathrm{SF}_{4}+\mathrm{F} \\
& \mathrm{e}^{-}+\mathrm{SF}_{4} \rightarrow \mathrm{e}^{-}+\mathrm{SF}_{3}+\mathrm{F} \\
& \mathrm{e}^{-}+\mathrm{SF}_{3} \rightarrow \mathrm{e}^{-}+\mathrm{SF}_{2}+\mathrm{F} \\
& \mathrm{e}^{-}+\mathrm{SF}_{2} \rightarrow \mathrm{e}^{-}+\mathrm{SF}+\mathrm{F} \\
& \mathrm{e}^{-}+\mathrm{SF} \rightarrow \mathrm{e}^{-}+\mathrm{S}+\mathrm{F}
\end{aligned}
$$

The experimental evidence of several publications 28,29 suggests that $\mathrm{SF}_{6}$ breaks down to $\mathrm{SF}_{2}$ very fast, on a time scale that is short with respect to that required for further reaction of the dissociation fragments. So, Ryan and Plumb 14 considered the production of $\mathrm{SF}_{2}$ as a "direct" process, within the framework of their model:

$\mathrm{e}^{-}+\mathrm{SF}_{6} \rightarrow \mathrm{e}^{-}+\mathrm{SF}_{2}+4 \mathrm{~F}$

The rate for reaction 7 was calculated by scaling the experimental value of Phelps and Van Brunt ${ }^{30}$, to fit the data of d'Agostino and Flamm ${ }^{23}$. The other possibility is to consider, in an explicit way, each of the dissociation steps (reactions 1 to 4$)^{17}$. A good description of the system is obtained using the dissociation rate of reference 30 , for reaction 1 in combination with the estimated electron density for the experiments of reference 23 , and considering reactions 2 to 4 to be fast enough so that the primary process (reaction 1) becomes the determinant step.

Both possibilities were considered in these simulations. In a first approach, $\mathrm{k}_{7}$, was set as $28 \mathrm{~s}^{-1}$ and $\mathrm{k}_{1}$ was set as zero, $\mathrm{k}_{\mathrm{j}}$ being the rate constant for reaction $\mathrm{j}$. In a second approach $\mathrm{k}_{1}$ was set as $56 \mathrm{~s}^{-1}, \mathrm{k}_{7}$ was set as zero and $\mathrm{k}_{2}$ to $\mathrm{k}_{6}$ were set an order of magnitude higher than $\mathrm{k}_{1}$. The integration of the rate equations shows that the results for $\mathrm{F}$ atom in the plasma region differ in about $7 \%$ and the values for the $\mathrm{SF}_{6}$ loss differ in less than $3 \%$. So, the comparison of modelling results with experimental data of etching rate and of $\mathrm{SF}_{6}$ conversion would 
not give insight to this point. The main differences are obtained for the $\mathrm{SF}_{2}$ and $\mathrm{SF}_{5}$ concentrations. Considering that the primary dissociation occurs by reaction 1 , the $\mathrm{SF}_{5}$ concentration is 1.8 times higher and the $\mathrm{SF}_{2}$ concentration is one order of magnitude lower. We interpret these results as an indication of the need to determine the intermediates concentration in the experimental system, in order to choose between one of the previous reaction sequences.

The effect of the electron number density on the modelling results was also investigated: a factor of two in this parameter changes the fluorine atom concentration by a factor of about 1.3. The results shown in this work were obtained with an electron number density of $1.0 \times$ $10^{10} \mathrm{~cm}^{-3}$ and considering reaction 7 as the main path of $\mathrm{SF}_{6}$ decomposition.

For the simulation conditions, a residence time of $1.0 \times 10^{-3} \mathrm{~s}$ is equivalent to a linear distance of $0.22 \mathrm{~cm}$ (origin of the plasma region) and a residence time of $2.25 \times 10^{-2} \mathrm{~s}$ is equivalent to $4.98 \mathrm{~cm}$ (end of the plasma region). The space beyond $5.0 \mathrm{~cm}$, equivalent to a linear time greater than $2.26 \times 10^{-2} \mathrm{~s}$, is the "afterglow" region, where the reactive species continue reacting towards equilibrium. Using this time scale, the comparative rates of individual processes for the main gaseous species are displayed in Table 2. As shown by these results, the species $\mathrm{SF}_{\mathrm{X}}$ recombine rapidly with $\mathrm{F}$ atoms. In fact, in pure $\mathrm{SF}_{6}$, the main reactions of $\mathrm{F}$ atoms are with $\mathrm{SF}_{\mathrm{X}}$ radicals:

$\mathrm{SF}_{\mathrm{x}}+\mathrm{F}+\mathrm{M} \rightarrow \mathrm{SF}_{\mathrm{x}+1}+\mathrm{M}$ with $\mathrm{x}=1,2,3,4,5$
The symbol $\mathrm{M}$ is used for a non reacting molecule, as usual. The main reactions are with $\mathrm{SF}_{2}, \mathrm{SF}_{4}$ and $\mathrm{SF}_{5}$, which take account for $80 \%-90 \%$ of fluorine consumption, depending on the distance of the discharge origin. The recombination reaction to give gaseous $\mathrm{F}_{2}$ represents about $10 \%$ in the origin of the plasma region and less than $8 \%$ in the middle of the reactor.

Surface reactions are artificially more important in the origin of the plasma region as a consequence of the boundary and initial conditions used in the computer simulation. For the selected residence times and initial values of [Si $]_{\text {initial }}$ and $\left[\mathrm{SF}_{6}\right]_{\text {initial, }}$ the number of $\mathrm{Si}$ atoms in the surface decreases rapidly. If the number of active sites had been considered constant during the whole process, the rate of attack to the surface would be proportional to the fluorine atoms concentration, since the solid phase association reaction:

$\mathrm{Si}+\mathrm{F} \rightarrow \mathrm{SiF} / \mathrm{Si}$

was considered as the rate determining step.

For pure $\mathrm{SF}_{6}$, the main stable gaseous products are $\mathrm{SiF}_{4}$ and $F_{2}$. These products are formed by the set of reactions:

$\mathrm{SiF}_{\mathrm{X}} / \mathrm{Si}+\mathrm{F} \rightarrow \mathrm{SiF}_{\mathrm{X}+1} / \mathrm{Si}$ with $\mathrm{x}=1,2,3$

$\mathrm{SiF}_{4} / \mathrm{Si} \rightarrow \mathrm{SiF}_{4}$

and

$2 \mathrm{~F}+\mathrm{M} \rightarrow \mathrm{F}_{2}+\mathrm{M}$

$2 \mathrm{~F}(\mathrm{~s}) \rightarrow \mathrm{F}_{2}(\mathrm{~s})$

$\mathrm{F}_{2}(\mathrm{~s}) \rightarrow \mathrm{F}_{2}$

Table 2. Contribution of individual reactions to kinetic processes in the plasma region.

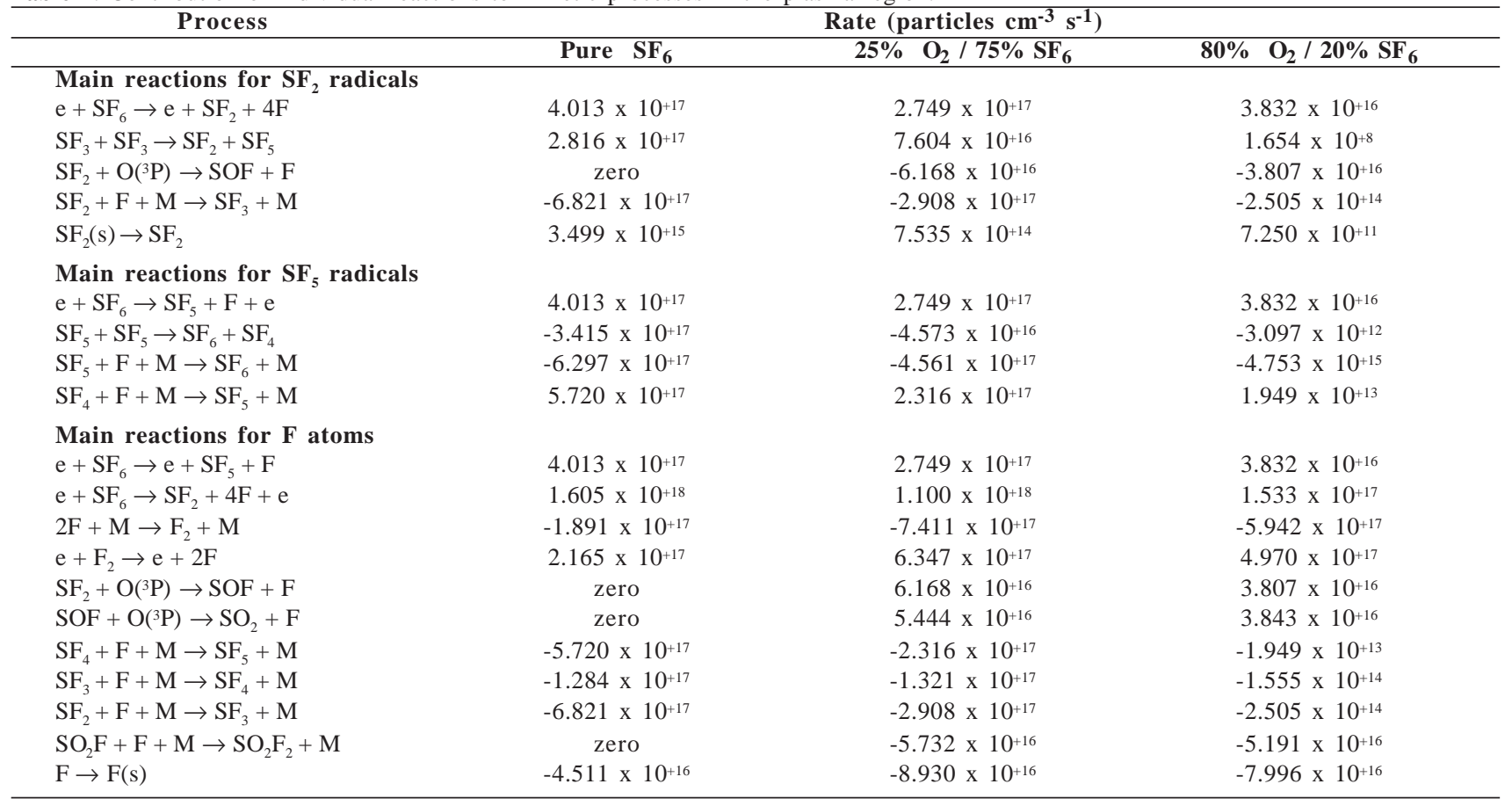


The symbols $\mathrm{SiF}_{\mathrm{n}+1} / \mathrm{Si}, \mathrm{F}(\mathrm{s})$ and $\mathrm{F}_{2}(\mathrm{~s})$ indicate adsorbed species on the surface.

As previously discussed, the recombination reactions of fluorine atoms with the $\mathrm{SF}_{\mathrm{x}}$ radicals, dominate the chemistry in the gaseous phase, limiting the conversion of $\mathrm{SF}_{6}$.

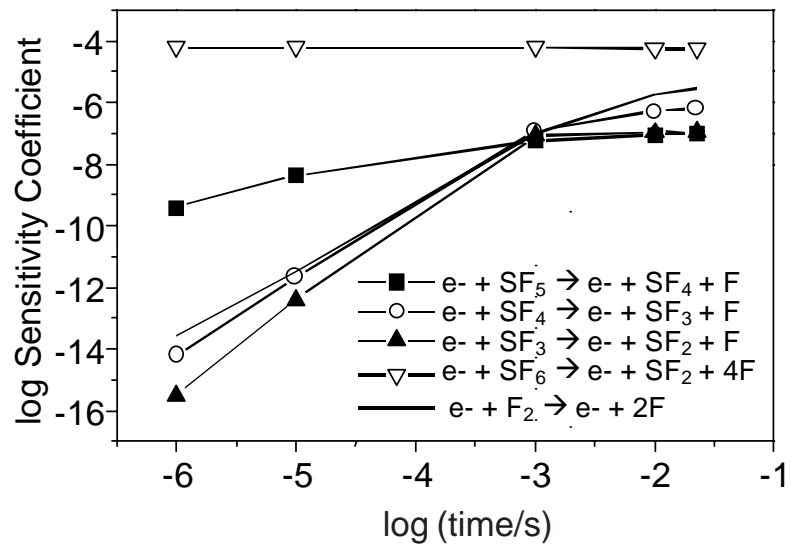

Figure 1. Sensitivity coefficients for atomic fluorine, relative to its production by $\mathrm{SF}_{\mathrm{x}}$ and $\mathrm{F}_{2}$ dissociation reactions, for the plasma etching of silicon in pure $\mathrm{SF}_{6}$ as a function of time.
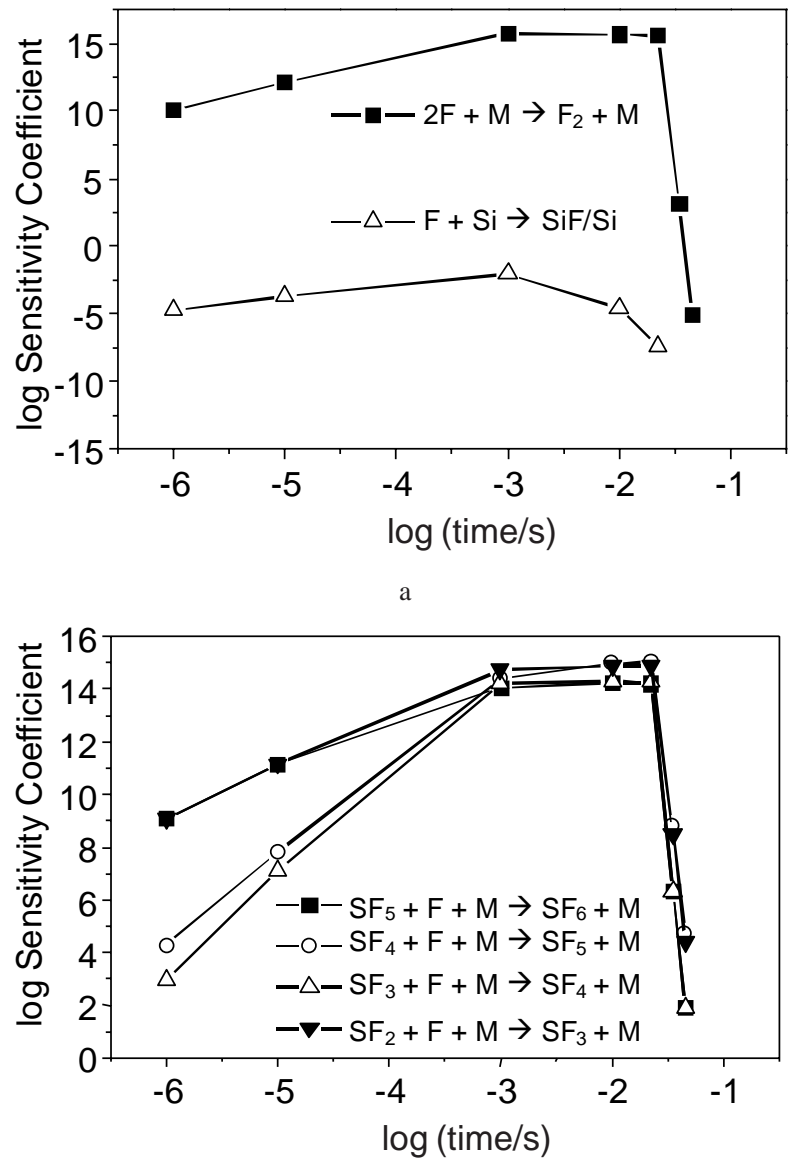

b

Figure 2. Comparison of sensitivity coefficients for atomic fluorine relative to consumption reactions : production of $\mathrm{F}_{2}$ and $\mathrm{SiF}(\mathrm{Si})$ (2a) and gas phase recombination reactions of $\mathrm{SF}_{\mathrm{x}}$ radicals $(2 \mathrm{~b})$, for the plasma etching of silicon in pure $\mathrm{SF}_{6}$.
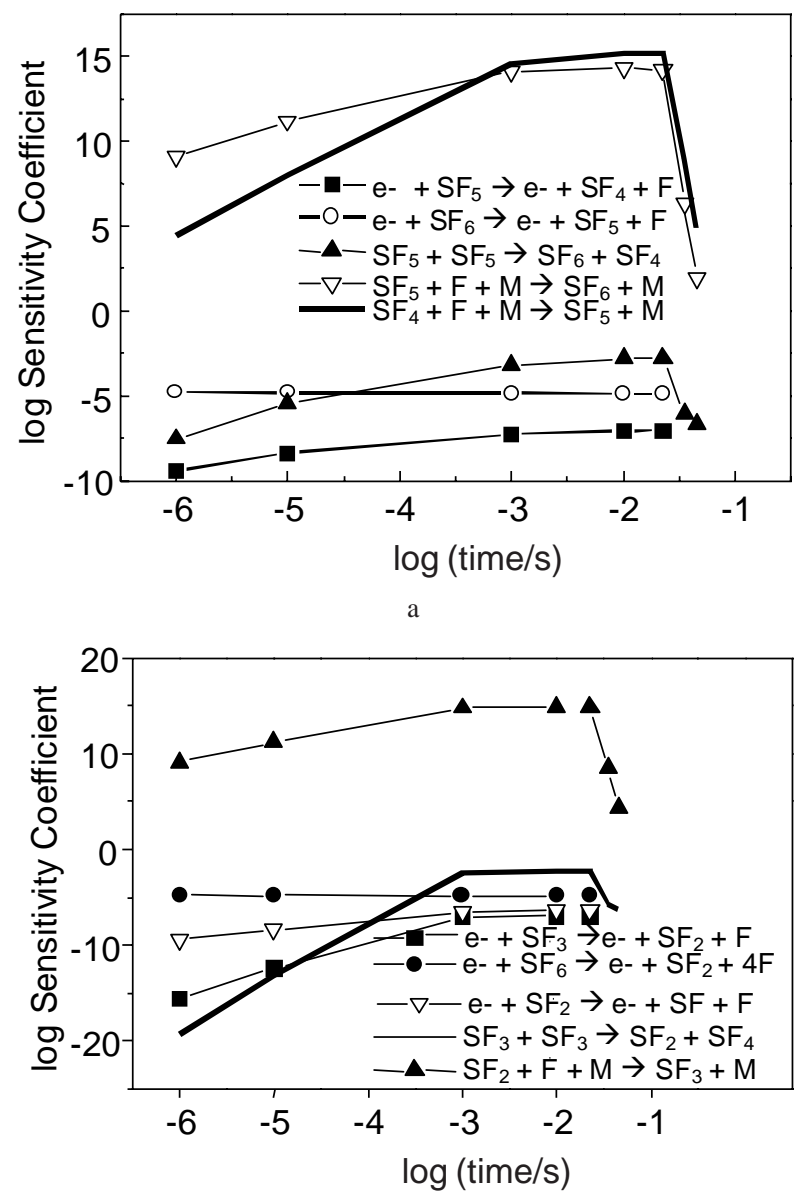

b

Figure 3. Sensitivity coefficients relative to the most relevant production and consumption reactions for $\mathrm{SF}_{5}(3 \mathrm{a})$ and for $\mathrm{SF}_{2}(3 \mathrm{~b})$ for the plasma etching of silicon in pure $\mathrm{SF}_{6}$ as a function of time.

For the $\mathrm{SF}_{5}$ radical the rate of recombination with fluorine atoms is about twice the rate of the self-reaction to give $\mathrm{SF}_{6}$ and $\mathrm{SF}_{4}$ radicals. A similar relation is observed for $\mathrm{SF}_{2}$ radicals.

In Figures 1 - 3, the sensitivity coefficients $\mathrm{S}_{\mathrm{ij}}$ for the main species towards the parameters of the model are shown. As for the $\mathrm{CF}_{4}$ plasma, the results stress the conclusions taken up to now: the shape of the sensitivity curves follows the general shape of the individual rate curves and the ratio between the $S_{i j}$ values is closely related to the contribution of each reaction.

When comparing the $S_{F, j}$ coefficients for the electron impact reactions (Figure 1), it is clear that, in these simulations conditions, the degree of products dissociation by electron impact is negligible, that is, the $\mathrm{SF}_{\mathrm{X}}$ radicals react rapidly with neutral species rather than dissociating to a $\mathrm{SF}_{\mathrm{X}-1}$ species plus $\mathrm{F}$ atom. Both Table 2 and Figure 2 show that the main sink of atomic fluorine is the molecular gas phase recombination.

Figures $3 \mathrm{a}$ and $3 \mathrm{~b}$ show the sensitivity coefficients for the main $\mathrm{SF}_{5}$ and $\mathrm{SF}_{2}$ reactions. 
By comparing the $S_{S F 5, j}$ values (Figure 3a) it is shown that, at the origin of the plasma region the main source of $\mathrm{SF}_{5}$ radicals is the dissociation of $\mathrm{SF}_{6}$, reaction 1 . At the end of the plasma region, recombination reactions become more relevant, mainly the $\mathrm{SF}_{4}+\mathrm{F}$ recombination:

$\mathrm{SF}_{4}+\mathrm{F}+\mathrm{M} \rightarrow \mathrm{SF}_{5}+\mathrm{M}$

A similar situation arises for $\mathrm{SF}_{2}$ (Figure $3 b$ ). The $S_{S F 2, j}$ coefficients for the $\mathrm{SF}_{6}$ dissociation, reaction 7 , and for reaction 4 , clearly reflects the larger contribution of the former to the formation of $\mathrm{SF}_{2}$ (Figure $3 \mathrm{~b}$ ). Both $S_{S F 5, e-+S F 6 \rightarrow e-}$ $+S F 5+F$ and $S_{S F 2, e-+S F 6 \rightarrow e-+S F 2+4 F}$ coefficients do not depend on the distance from the origin, due to the low conversion of $\mathrm{SF}_{6}$. Again, at the origin of the plasma region, $\mathrm{SF}_{2}$ radicals are mainly formed by electron impact dissociation reactions. Nevertheless, for larger concentrations of intermediate products, the recombination reactions of the other radicals become a rather important source of $\mathrm{SF}_{2}$.

The $S_{S F 2}$ and the $S_{S F 5}$ coefficients for the gas phase recombination reactions :

$\mathrm{SF}_{2}+\mathrm{F}+\mathrm{M} \rightarrow \mathrm{SF}_{3}+\mathrm{M}$

and

$\mathrm{SF}_{5}+\mathrm{F}+\mathrm{M} \rightarrow \mathrm{SF}_{6}+\mathrm{M}$

are very similar since the rates for both processes are also very similar and are higher than the coefficients for further electron impact dissociation of $\mathrm{SF}_{2}$ and $\mathrm{SF}_{5}$.

\section{$\mathrm{SF}_{6} / \mathrm{O}_{2}$ Mixtures}

The experimental evidences 23 show that $\mathrm{SO}_{2} \mathrm{~F}_{2}, \mathrm{SOF}_{4}$ and $\mathrm{SO}_{2}$ appear as the main new products. Also, as $\mathrm{O}_{2}$ concentration increases relatively to $\mathrm{SF}_{6}$ concentration, the amount of $\mathrm{SO}_{2} \mathrm{~F}_{2}$ increases relatively to $\mathrm{SOF}_{4}$. These results were also observed in our previous simulation ${ }^{19}$.

In the presence of $\mathrm{O}_{2}$, oxygen atoms compete with $\mathrm{F}$ atoms for the $\mathrm{SOF}_{\mathrm{X}}$ and $\mathrm{SF}_{\mathrm{X}}$ species. The result is that, in the presence of $\mathrm{O}_{2}$, the fluorine atom concentration increases up to a maximum value. The further decrease in $\mathrm{F}$ concentration with added oxygen is due to dilution and to the decrease of electron energy (the latter causes the $\mathrm{SF}_{6}$ electron dissociation rate to decrease).

Figure 4 a shows the sensitivity coefficients for the main atomic fluorine formation reactions. At the origin of the plasma region, dissociation of $\mathrm{SF}_{6}$ is clearly the most relevant process. As the atomic oxygen concentration increases, their reactions with $\mathrm{SF}_{5}$ and $\mathrm{SF}_{2}$ to form $\mathrm{SOF}_{4}+\mathrm{F}$ and $\mathrm{SOF}+\mathrm{F}$, respectively, become competitive with electron impact dissociation and other $\mathrm{SF}_{\mathrm{X}}$ reactions.

As in the pure $\mathrm{SF}_{6}$ system, both the individual rates and the sensitivity coefficients $\mathrm{S}_{\mathrm{F}}$ are quite similar for the
$\mathrm{SF}_{\mathrm{x}}+\mathrm{F}$ recombination reactions, being the largest sensitivity coefficient found for the gas phase recombination of atomic fluorine with $\mathrm{SF}_{5}$ (Figure 3a), followed by the coefficients for the recombination reactions with $\mathrm{SF}_{2}, \mathrm{SF}_{4}$ and $\mathrm{SF}_{3}$ (Figure $4 \mathrm{~b}$ ). Since oxygen atoms compete with fluorine atoms for these radicals, the relative importance of $F_{2}$ gas phase formation:

$2 \mathrm{~F}+\mathrm{M} \rightarrow \mathrm{F}_{2}+\mathrm{M}$

becomes larger (see Figure $4 \mathrm{~b}$ and Table 2), being about $40 \%$ in the plasma region.

Figures $5 \mathrm{a}$ and $5 \mathrm{~b}$ show the $\mathrm{SO}_{2} \mathrm{~F}_{2}$ and $\mathrm{SOF}_{4}$ sensitivity coefficients, calculated for the main parameters. The sensitivity coefficients confirm that the main path of formation of $\mathrm{SO}_{2} \mathrm{~F}_{2}$ is the reaction with $\mathrm{O}\left({ }^{3} \mathrm{P}\right)$ atoms:

$\mathrm{SOF}_{2}+\mathrm{O} \rightarrow \mathrm{SO}_{2} \mathrm{~F}_{2}$

which is faster than $\mathrm{SO}_{2} \mathrm{~F}$ reaction with $\mathrm{F}$ atoms:

$\mathrm{SO}_{2} \mathrm{~F}+\mathrm{F}+\mathrm{M} \rightarrow \mathrm{SO}_{2} \mathrm{~F}_{2}+\mathrm{M}$
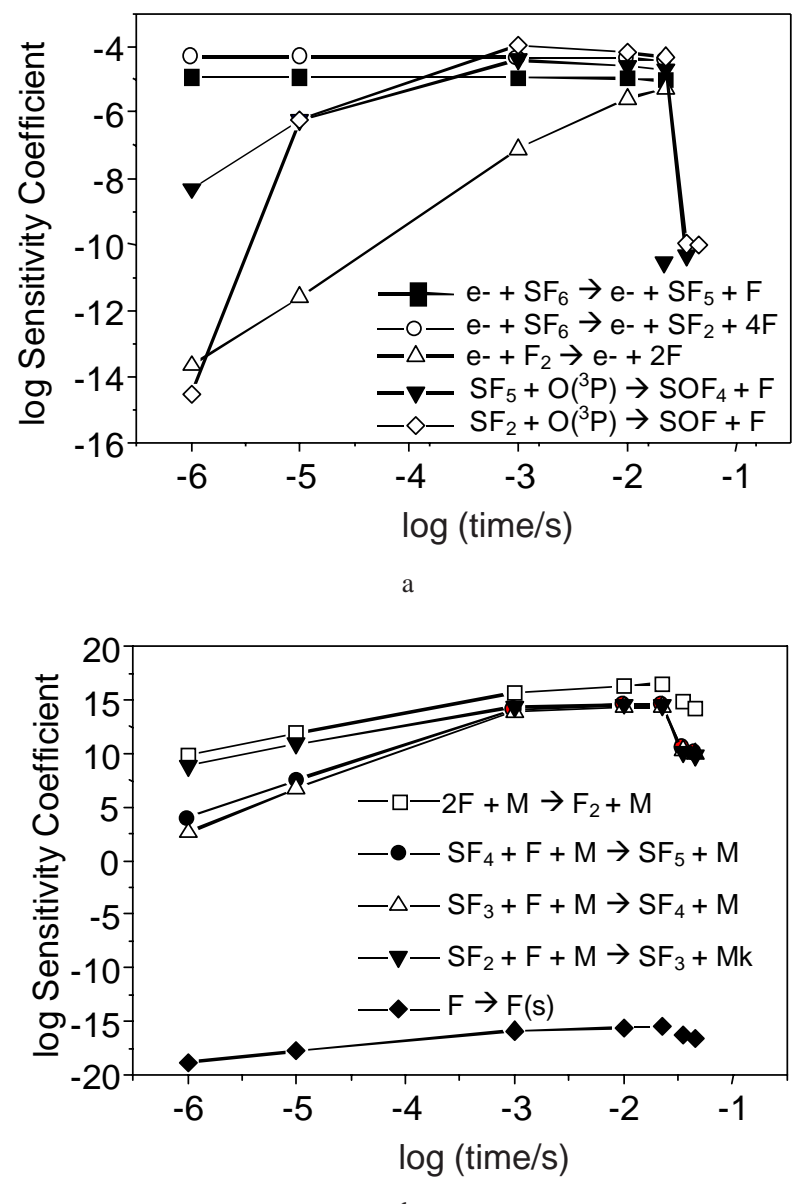

Figure 4. Sensitivity coefficients for atomic fluorine relative to the most relevant production reactions (4a) and consumption reactions (4b) for the plasma etching of silicon in a mixture $75 \% \mathrm{SF}_{6}$ and $25 \%$ $\mathrm{O}_{2}$ as a function of time. 


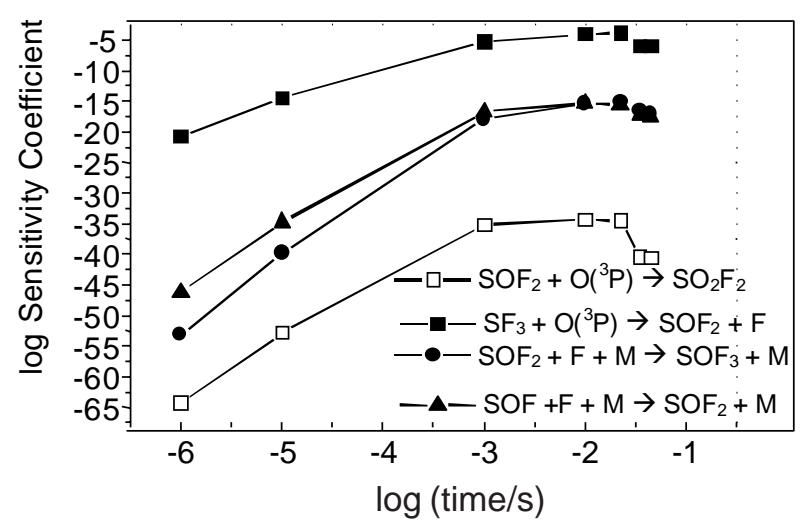

a

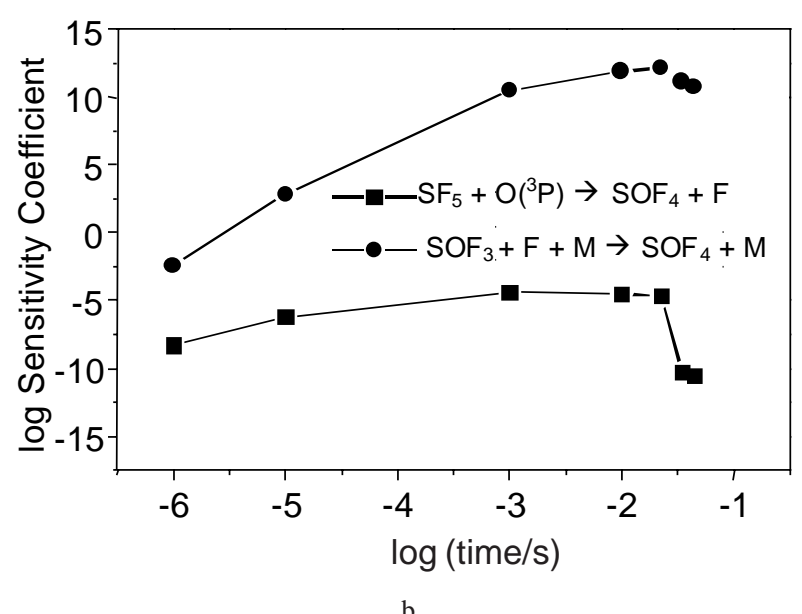

Figure 5. Sensitivity coefficients relative to the most relevant reactions the production and consumption of $\mathrm{SO}_{2} \mathrm{~F}_{2}(5 \mathrm{a})$ and $\mathrm{SOF}_{4}$ (5b) for the plasma etching of silicon in a mixture $75 \% \mathrm{SF}_{6}$ and $25 \%$ $\mathrm{O}_{2}$ as a function of time.

Fluorine and oxygen atoms compete for $\mathrm{SOF}_{2}$, the second reaction giving $\mathrm{SO}_{2} \mathrm{~F}_{2}$, being clearly more important in determining $\mathrm{SO}_{2} \mathrm{~F}_{2}$ concentration. Reaction with atomic fluorine:

$\mathrm{SOF}_{2}+\mathrm{F}+\mathrm{M} \rightarrow \mathrm{SOF}_{3}+\mathrm{M}$

forms $\mathrm{SOF}_{3}$, which further reacts to give $\mathrm{SOF}_{4}$. The main paths forming $\mathrm{SOF}_{4}$ are:

$\mathrm{SF}_{5}+\mathrm{O}\left({ }^{3} \mathrm{P}\right) \rightarrow \mathrm{SOF}_{4}+\mathrm{F}$

$\mathrm{SOF}_{3}+\mathrm{F}+\mathrm{M} \rightarrow \mathrm{SOF}_{4}+\mathrm{M}$

The relative contributions of reaction 23 , in comparison with reaction 22 , increases as $\mathrm{SOF}_{3}$ concentration grows up in the reactor. For the $25 \% \mathrm{O}_{2}$ mixture, the $S_{S O F 4, S O F 3+F \rightarrow S O F 4} / M$ coefficient is higher than the $S_{S O F 4, S F 5+O(3 P) \rightarrow S O F 4+F}$, confirming that the main path of formation of $\mathrm{SOF}_{4}$ is through the $\mathrm{SOF}_{3}+\mathrm{F}$ reaction.

In Figure 6 the rate of formation of gaseous $\mathrm{SiF}_{4}$ as function of the distance from the discharge origin and the mole percent of $\mathrm{O}_{2}$ in the feed is displayed. A minimum is

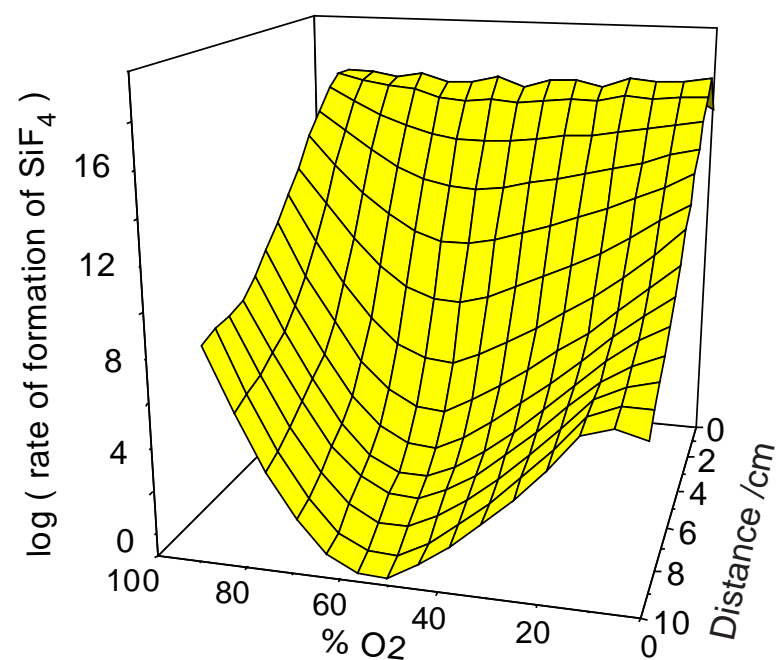

Figure 6. Rate of formation of gaseous $\mathrm{SiF}_{4}$ as a function of the distance from the discharge origin and the mole percent of $\mathrm{O}_{2}$ in the feed.

observed in this surface, which corresponds to nearly $50 \%$ of $\mathrm{O}_{2}$ in the afterglow region. From the simulated data, the atomic fluorine concentration is maximum for $50 \%$ of oxygen, so that the rate of etching is also maximum and $\mathrm{SiF}_{4}$ is almost totally formed in the first centimetres of the reactor. In other conditions, the etching rate is slower and the $\mathrm{SiF}_{4}$ formation is observed through the total length of the reactor. So, the atomic fluorine is considered the active etching agent in this modelling, while the primary etching reaction is rate controlling.

As expected, the concentration of atomic fluorine and the rate of formation of $\mathrm{SiF}_{4}$, in the plasma region, are higher for the $\mathrm{SF}_{6}$ and $\mathrm{SF}_{6} / \mathrm{O}_{2}$ systems than for the $\mathrm{CF}_{4}$ and $\mathrm{CF}_{4} / \mathrm{O}_{2}$ systems ${ }^{1 b}$. However, in the afterglow region, the inverse is observed, mainly because the recombination of $\mathrm{F}$ atoms with the $\mathrm{SF}_{\mathrm{X}}$ radicals is faster than the reactions with $\mathrm{CF}_{3}$ and $\mathrm{CF}_{2}$. For the boundary conditions of these simulations, the final concentrations of $\mathrm{SiF}_{4}$ are equal because it is limited by the total number of silicon atoms used in the simulation.

\section{Conclusions}

The numerical integration of rate equations has been applied to the study of the gas-phase decomposition of pure $\mathrm{SF}_{6}$ and $\mathrm{SF}_{6} / \mathrm{O}_{2}$ mixtures in the presence of silicon.

As expected, the results of this computer simulation are in good agreement with previous results from literature and provide complementary information about these systems. The rate of production and the sensitivity analysis, as well as the computed concentrations, show that the major features of plasma etching of silicon are explained in terms of the gas-phase reactions. 
As for the $\mathrm{CF}_{4}$ and $\mathrm{CF}_{4} / \mathrm{O}_{2}$ systems, the model was proposed to reproduce the experimental conclusion that atomic fluorine is the active etching agent. The primary etching reaction appears to be the most significant process and the sequential fluorination reactions have no significant sensitivities since their rates were purposely chosen not to be rate controlling.

The kinetic analysis shows that many key processes are poorly known and need a better determination. The major uncertainties in the gas phase chemistry are the branching ratios for the primary dissociation processes, the cross sections for electron impact dissociations and the electron number densities.

A more complete model should include a detailed description of the surface chemistry and the transport of radicals and ions, which were crudely parameterised in this work. Also, the formulation of such a model must involve the consideration of the energy distribution of particles and temperature gradients, reactions of electronically and vibrationally excited species, positive and negative ions chemistry and polimerization reactions.

\section{Acknowledgements}

The authors thank partial financial support from $\mathrm{CNPq}$ and FAPERJ. They also thank Prof. T. Turányi (Central Research Institute of Chemistry, Budapest, Hungary) for a free copy of KINAL package and Prof. Gerardo Gerson B. de Souza (DFQ/IQ/UFRJ) for his interest in this project.

\section{References}

1. (a) Bauerfeldt, G. F.; Arbilla, G. J. Braz. Chem. Soc. 2000 (in press). (b) Bauerfeldt, G. F.; Arbilla, G. Quím. Nova. 1998, 21, 25.

2. Mogab, C. J.; Adams, A. C.; Flamm, D. L. J. Appl. Phys.1978, 49, 3796.

3. Kushner, M. J. J. Appl. Phys. 1982, 53, 2923.

4. Edelson, D.; Flamm, D. L. J. Appl. Phys. 1984, 56, 1522.

5. Plumb, I. C.; Ryan, K. R. Plasma Chem. Plasma Process. 1986, 6, 205.

6. Ryan, K. R.; Plumb, I. C. Plasma Chem. Plasma Process. 1986, 6, 233.

7. Plumb, I. C.; Ryan, K. R. Plasma Chem. Plasma Process. 1986, 6, 247.

8. Kline, L. E. IEEETrans. Plasma Sci. 1986, PS-14, 145.
9. Anderson, H. M.; Merson, J. A.; Light, R.W. IEEE Trans. Plasma Sci. 1986, PS-14, 156.

10. Venkatesan, S. P.; Trachtenberg, I.; Edgard, T. F. J. Electrochem. Soc. 1987, 134, 3194 .

11. Ryan, K. R.; Plasma Chem. Plasma Proc. 1989, 9, 483.

12. Economou, D. J.; Park, S. K.; Williams, G. J. Electrochem. Soc. 1987, 134, 3194.

13. Venkatesan, S. P.; Edgard, T. F.; Trachtenberg, I. J. Electrochem. Soc. 1989, 136, 2536.

14. Ryan, K. R.; Plumb, I. C. Plasma Chem. and Plasma Process. 1990, 10, 207.

15. Lii, Y. J.; Jorné, J.; Cadien, K. C.; Schoenholtz, Jr., J.E.; J. Electrochem. Soc. 1990, 137, 3633.

16. Park, S. K.; Economou, D. J. J. Electrochem. Soc. 1991, 138, 1499.

17. Kopalidis, P. M.; Jorné, J. J. Electrochem. Soc. 1993, 140, 3037.

18. Khairallah, Y.; Khonsari-Arefi, F; Amouroux, J. Pure Appl. Chem. 1994, 66, 1353.

19. Bauerfeldt, G. F.; Arbilla, G. Quím. Nova. 1998, 21, 34.

20. (a) Ryan, K. R.; Plumb, I. C. Crit. Rev. Solid State Mater CS 1988, 15, 153. (b) Manos, D. M.; Flamm, D. L. Plasma Etching: An Introduction; Academic Press; San Diego, CA, 1989.

21. Turányi, T. J. Math. Chem. 1990, 5, 203.

22. Smolinsky, G.; Flamm, D. L. J. Appl. Phys. 1979, 50, 4982.

23. d'Agostino, R.; Flamm, D. L. J. Appl. Phys. 1981, 52, 162.

24. Kaps, P.; Rentrop, P. Numer. Math. 1979, 33, 55.

25. Turányi, T. Comput. Chem. 1990, 14, 3, 253.

26. (a) Steinfield, J. I.; Francisco, J. S.; Hase, W. L. Chemical Kinetics and Dynamics; Prentice Hall, Englewood Cliffs; New Jersey, 1989. (b) Pilling, M. J.; Smith, I. W. M. Modern Gas Kinetics. Theory, Experiment and Application; Blackwell Scientific Publications; Oxford, 1987. (c) Hirst, D. M. A Computational Aproach to Chemistry; Blackwell Scientific Publications; Oxford, 1990.

27. Valkó, P.; Vajda, S. Comput. Chem. 1984, 8, 255.

28. Ryan, K. R.; Plumb, I. C. Plasma Chem. Plasma Proc. 1988, 8, 263.

29. Ryan, K. R.; Plumb, I. C. Plasma Chem. Plasma Proc. 1988, 8, 281.

30. Phelps, A. V.; Van Brunt, R. J. J. Appl. Phys. 1988, 64, 4269. 